\title{
A RELAÇÃO DA FAMÍLIA COM CRIANÇAS HOSPITALIZADAS NA UNIDADE DE TERAPIA INTENSIVA NEONATAL COM A EQUIPE DE ENFERMAGEM
}

\author{
THE RELATIONSHIP OF THE FAMILY WITH \\ CHILDREN HOSPITALIZED IN NEONATAL INTENSIVE \\ CARE UNIT AND THE TEAM OF NURSING
}
LA RELACIÓN DE LA FAMILIA CON LOS NIÑOS HOSPITALIZADOS EN UNIDAD DE CUIDADOS INTENSIVOS NEONATALES CON UN EQUIPO DE ENFERMERÍA

Júlia Martins Azevedo Maia*, Larissa Barbas da Silva*, Evelyn de Andrade Santiago Ferrari**

\begin{abstract}
Autor correspondente: Júlia Martins Azevedo Maia - juhmaia_@hotmail.com
*Graduanda de Enfermagem da Escola Bahiana de Medicina e Saúde Pública, **Enfermeira. Especialista em Enfermagem.

Docente de Enfermagem da Escola Bahiana de Medicina e Saúde Pública
\end{abstract}

\section{Resumo}

O processo de internação em uma unidade de terapia intensiva neonatal é uma situação bastante delicada e frágil tanto para a família quanto para o recém-nascido, surgindo sentimentos indesejáveis e angustiantes. $O$ estudo trata de uma pesquisa bibliográfica do tipo integrativa, realizado no período de 2003 a 2013, que tem por objetivo identificar como acontece a relação da equipe de enfermagem com a família de crianças hospitalizadas na Unidade de Terapia Intensiva Neonatal. Os dados foram analisados em três categorias: a família vivenciando o processo de internação; a interação entre equipe de enfermagem e família; a família inserida no cuidado ao recém-nascido hospitalizado. Os resultados apontam a importância da equipe de enfermagem em aproximar a família na participação do cuidado ao neonato através do acolhimento, sendo um dos principais métodos em iniciar uma assistência humanizada. Assim, é necessário o estabelecimento de uma comunicação efetiva entre a equipe de enfermagem e a família, preservando a singularidade de cada criança. O estudo evidenciou que a participação da família no cuidado humanizado ao recém-nascido é ainda um tema que precisa receber uma atenção maior. A equipe de enfermagem não só deve incluir a família na sua assistência, 
como também se sensibilizar e enfrentar as dificuldades em inseri-la no cuidado ao RN, sempre em busca de conhecimentos teóricos que auxiliem nas mudanças necessárias.

Palavras-chave: Unidades de Terapia Intensiva Neonatal; Unidades de Terapia Intensiva Pediátrica; Família; Enfermagem.

\begin{abstract}
The process of hospitalization in a Neonatal Intensive Care Unit is a very delicate and fragile situation for the family and the newborn, causing undesirable and distressing feelings. The study is an integrative bibliographic research, accomplished in the period of 2003 to 2013 , which aims to identify the relationship between the nursing staff and the family of the children hospitalized in the Neonatal Intensive Care Unit. The data were analyzed according to three categories: the family experience in the hospitalization process; the interaction between nursing staff and family; the family included in the care of the hospitalized newborns. The results indicate the importance of the nursing team getting close to the family and the care with the newborn through a better admission which is one of the main methods to begin a humanized assistence. This way, it is necessary the establishment of an effective communication between the nursing staff and family, preserving the singularity of each child. The study showed that family participation in the humanized care of the newborn is still an issue that needs to receive greater attention. The nursing staff should not only include family in her care, as well as to sensitize and face difficulties in inserting it in the newborn care, always searching for theoretical knowledge that helps in necessary changes.

Kepwords: Neonatal Intensive Care Units, Pediatric Intensive Care Units; Family; Nursing.
\end{abstract}

\title{
Resumen
}

El proceso de hospitalización en una unidad de cuidados intensivos neonatales es una situación muy delicada y frágil, tanto para la familia como para el recién nacido, apareciendo sentimientos no deseados y angustiantes. El estudio es una revisión de la literatura de tipo integral, realizado entre 2003-2013, que tiene como objetivo identificar como es la relación entre el personal de enfermería a la familia de los niños hospitalizados en la Unidad de Cuidados Intensivos Neonatales. Los datos fueron analizados en tres categorías: la familia experimentar el proceso de hospitalización, la interacción entre el personal de enfermería y la familia, la familia se coloca en el cuidado de los cuidados del recién nacido hospitalizado. Los resultados indican la importancia del equipo de enfermería en acercarse a la participación de la familia en la atención al recién nacido a través de la acogida, uno de los principales métodos para iniciar un asistencia humanizado. Por lo tanto, el establecimiento de una comunicación efectiva entre el personal de enfermería y la familia es necesario, preservando la singularidad de cada niño. El estudio mostró que la participación de la familia en el cuidado del recién nacido humanizado es todavía un tema que debe recibir mayor atención. El personal de enfermería no sólo debe incluir a la familia en su cuidado, además de ser sensible y tener dificultades para insertarlo en el cuidado de los niños, siempre en busca de conocimientos teóricos para ayudar en los cambios necesarios.

Palabras Clave: Unidades de Cuidados Intensivos Neonatales; Unidad de Cuidados Intensivos Pediátrica; Familia; Enfermería. 


\section{INTRODUÇÃO}

A Unidade de Terapia Intensiva Neonatal (UTIN) é um local destinado a receber recém-nascidos (RN) que necessitam de cuidados especiais. Diversos são os fatores que podem ser apontados como causa de internação, como prematuridade, má formação congênita e incompatibilidade sanguínea, ocasionando icterícia. Para fornecer esses cuidados, a UTIN deve dispor de uma equipe capacitada, espaço físico adequado, materiais e equipamentos sempre disponíveis e em funcionamento. ${ }^{(1)}$

A assistência ao RN em UTI neonatais tem passado por importantes transformações. Com base na filosofia do cuidado centrado na família, o suporte à família e participação dos pais nos cuidados diretos ao RN, assim como a inclusão deles nas decisões sobre seu filho, devem ser uma das prioridades nos serviços de Neonatologia. A internação prolongada dos bebês e a privação do ambiente aumentam o estresse dos pais e da família, podendo prejudicar o estabelecimento do vínculo e apego. ${ }^{(2)}$

No Brasil, foi apenas a partir do final da década de 1980, que a família começou a participar do cuidado à criança hospitalizada. ${ }^{(3)} \mathrm{O}$ fator determinante em defesa dos direitos da criança foi a publicação do Estatuto da Criança e do Adolescente em 1990, o qual resgata o direito da permanência em tempo integral de um dos pais ou responsável, nos casos de internação de criança ou adolescente, proporcionando condições para a permanência do mesmo. ${ }^{(4)}$

Apesar da Lei n 8069 de 1990, em seu artigo 12, estabelecer esse direito, este procedimento ainda não é uma realidade em muitas instituições e estados brasileiros, mesmo sabendo-se que a presença da mãe é o método mais efetivo para minimizar os traumas psicológicos da hospitalização. ${ }^{(5)}$

O processo de humanização nas unidades neonatais surgiu a partir do estabelecimento do alojamento conjunto, onde as mães permaneciam em contato direto com o filho recém-nascido. Atualmente, essas unidades são consideradas locais destinados a bebês que, mesmo em incubadoras, são assistidos por uma equipe multidisciplinar. ${ }^{(6)}$

O Ministério da Saúde lançou, por meio da Portaria $n^{\circ} 693$, de 5 de julho de 2000, a Norma de Atenção Humanizada ao Recém-Nascido de Baixo Peso (Método Canguru), com o objetivo de contribuir para a mudança de postura dos profissionais, e visando à humanização da assistência ao recém-nascido. A partir do nascimento do bebê, e havendo necessidade de permanência na Unidade de Terapia Intensiva Neonatal (UTIN) e/ou Unidade de Cuidados Intermediários Neonatal (UCIN), especial atenção é dada no sentido de estimular a entrada dos pais nesses locais, e de estabelecer contato pele a pele com o bebê, de forma gradual e crescente, de maneira segura e agradável para ambos. ${ }^{(7)}$

O processo de hospitalização para os pais de crianças internadas desencadeia reações muito consistentes, podendo ser iniciada com a descrença, especialmente quando é uma doença grave. Os pais tendem a reagir com raiva e culpa pela doença apresentada pelo filho, desafiando a sua capacidade como cuidadores. ${ }^{(8)}$

Durante a internação do RN na UTIN, ocorre o rompimento do vínculo entre mãe e recém-nascido, o que muitas vezes compromete a afetividade entre pais e filhos. Além da separação corporal, o contato físico entre os dois se torna esporádico e à distância, em um ambiente frio e hostil.(5)

Dentro da UTIN deve existir uma interação entre os profissionais da equipe de saúde e destes com a família, propiciando assim, uma UTIN humanizada, onde o RN receberá toda atenção e carinho da equipe. ${ }^{(1)}$ Em relação à equipe de enfermagem, esta assume um leque de atribuições e responsabilidades que, por sua vez, demandam capacidades essenciais para avaliar, entender e apoiar, com segurança, o RN e a sua família durante esse tempo crítico. ${ }^{(2)}$

A presença dos pais contribui para o cuidado ao filho hospitalizado, estabelecendo vínculo afetivo 
mãe-filho, e principalmente, ajudando na redução do estresse causado pela situação e no preparo para o cuidado em domicílio. Mas para os pais, além da internação significar vida e segurança pela promoção à saúde diante de avançados recursos, pode significar medo e insegurança diante dos seus sentimentos de impotência e do desconhecido. Implementar uma prática que inclua a família no contexto, exige do profissional que ele consiga captar as nuanças da experiência da família, desfazendo-se da imagem de que o cuidado deve ser realizado com os indivíduos e não com o grupo familiar. ${ }^{(9)}$

Visando garantir uma adequada qualidade na avaliação, classificação, tratamento e acompanhamento das doenças e problemas que afetam a saúde dos menores de cinco anos de idade, foi criada a Atenção Integrada às Doenças Prevalentes na Infância (AIDPI), sendo considerada a principal intervenção disponível para melhorar as condições de saúde na infância. Contudo, é importante para o profissional de saúde, em especial o enfermeiro, ter o conhecimento deste manual no que diz respeito a um olhar crítico e aprimorado sobre o $\mathrm{RN}$ e sua família. ${ }^{(10)}$

Para a assistência ao familiar e RN como seres holísticos, os profissionais de saúde necessitam compreender o problema, planejar e promover assistência eficiente no processo de formação de vínculo. Devem observar a singularidade de cada caso, englobando os aspectos biopsicossociais, pois cada mãe tende a reagir influenciada pela herança cultural e por suas vivências. Portanto, essa assistência deve ser baseada no conhecimento de reações, sentimentos, significados, hábitos, valores e costumes. ${ }^{(5)}$

O presente estudo objetivou discutir como acontece a relação da equipe de enfermagem com a família de crianças hospitalizadas na Unidade de Terapia Intensiva Neonatal.

\section{METODOLOGIA}

Trata-se de uma pesquisa bibliográfica do tipo integrativa, buscando compreender sob o olhar de diversos autores, a relação da família na Unidade de Terapia Intensiva Neonatal e a equipe de enfermagem.

A pesquisa bibliográfica trata de um levantamento de toda bibliografia já publicada, em forma de livros, publicações avulsas e imprensa escrita. Sua finalidade é colocar o pesquisador em contato direto com tudo aquilo que foi escrito sobre determinado assunto, com o objetivo de permitir ao cientista "o reforço paralelo na análise de suas pesquisas ou manipulação de suas informações". (11) A principal vantagem da pesquisa bibliográfica reside no fato de permitir ao investigador a cobertura de uma gama de fenômenos muito mais ampla do que aquela que poderia pesquisar diretamente..$^{(12)}$

A revisão integrativa inclui a análise de pesquisas relevantes, que dão suporte para a tomada de decisão e a melhoria da prática clínica, possibilitando a síntese do estado do conhecimento de um determinado assunto, além de apontar lacunas do conhecimento que precisam ser preenchidas com a realização de novos estudos. Este método de pesquisa permite a síntese de múltiplos estudos publicados e possibilita conclusões gerais a respeito de uma particular área de estudo. ${ }^{(13)}$

Para o desenvolvimento do presente estudo, foi realizada a coleta de dados através de consulta no Descritores em Ciências da Saúde (DeCS), pois os mesmos oferecem uma linguagem única na indexação de artigos científicos. Inicialmente, utilizou-se o descritor "Unidades de Terapia Intensiva Neonatal", direcionando o rastreamento para o BVS (Biblioteca Virtual em Saúde), onde foram encontrados 183 trabalhos pelo BDENF (Base de Dados de Enfermagem) e selecionados apenas 03 . No banco de dados do LILACS (Literatura Latino Americana e do Caribe em Ciências da Saúde), foram encontrados 585 trabalhos. No entanto, no que diz respeito à relação enfermagem, família e neonatal, foram encontrados 39 artigos e usados 08 , utilizando os descritores enfermagem e família. Quando se pesquisou apenas o descritor família, encontraram-se 83 artigos e selecionaram-se 02 . Posteriormente, usou-se o descritor "Unidades de Terapia Intensiva Pediátrica", onde a pesquisa foi direcionada para 
o banco de dados LILACS com o descritor família, sendo encontrados 51 artigos, porém selecionados O2 deles.

Os critérios de inclusão adotados foram: ser estudo de campo, com exploração qualitativa ou revisão de literatura, publicado no período de 2003 a 2013; todos os trabalhos deveriam estar publicados em revistas indexadas na língua portuguesa e serem gratuitos; ter como um dos sujeitos de pesquisa a família e/ou enfermeiro; ser foco de exploração do estudo a experiência materna/familiar na UTIN e/ou abordar ações/atitudes/habilidades do enfermeiro que influenciam o enfrentamento familiar na UTIN.

Os critérios de exclusão para a pesquisa foram: artigos que não estivessem de acordo com os objetivos propostos pelo estudo; estar em outro idioma; estar incompleto, ou apenas com resumo.

A aprovação pelo Comitê de Ética em Pesquisa não foi necessária por não se tratar de uma pesquisa com seres humanos.

\section{RESULTADOS E DISCUSSÃO}

Considerando-se as repetições de artigos nas diferentes bases de dados e os critérios de inclusão e exclusão, foram coletados 15 artigos científicos. Os artigos foram lidos em sua íntegra e para a organização dos mesmos, foi utilizado o sistema de fichamento, facilitando o estudo e sua organização, além de dinamizar a pesquisa.

Tabela 1 - Distribuição das pesquisas utilizadas na elaboração dos resultados, 2013.

(continua)

\begin{tabular}{|c|c|c|c|c|}
\hline Título & AUTOR & $\begin{array}{c}\text { ANO DE } \\
\text { Publicação }\end{array}$ & TIPO DE PESQUISA & $\begin{array}{c}\text { Local de PublicaçÃo/ } \\
\text { REVISTA }\end{array}$ \\
\hline $\begin{array}{c}\text { Vivências de Familiares no } \\
\text { Processo de Nascimento e } \\
\text { Internação de seus Filhos em UTI } \\
\text { Neonatal }\end{array}$ & $\begin{array}{l}\text { Oliveira } \\
\text { K,Veronez M, } \\
\text { Higaurashi IH, } \\
\text { Corrêa DAM. }\end{array}$ & 2013 & $\begin{array}{c}\text { Estudo de Caso } \\
\text { Descritivo, } \\
\text { Abordagem } \\
\text { Qualitativa }\end{array}$ & $\begin{array}{c}\text { Revista de Enfermagem } \\
\text { Escola Anna Nery }\end{array}$ \\
\hline $\begin{array}{l}\text { Acolhimento na Unidade } \\
\text { Neonatal: Percepção da Equipe } \\
\text { de Enfermagem }\end{array}$ & $\begin{array}{l}\text { Costa R, Klock } \\
\text { P, Locks } \mathrm{MOH} \text {. }\end{array}$ & 2012 & $\begin{array}{c}\text { Estudo de Caso } \\
\text { Exploratório } \\
\text { Descritivo, } \\
\text { Abordagem } \\
\text { Qualitativa }\end{array}$ & $\begin{array}{c}\text { Revista de Enfermagem } \\
\text { UERJ }\end{array}$ \\
\hline $\begin{array}{c}\text { A Percepção do Acompanhante } \\
\text { sobre a Humanização da } \\
\text { Assistência em uma Unidade } \\
\text { Neonatal }\end{array}$ & $\begin{array}{c}\text { Spir EG, } \\
\text { Soares AVN, } \\
\text { Wei CY, } \\
\text { Aragaki IMM, } \\
\text { Kurcgant P. }\end{array}$ & 2011 & $\begin{array}{l}\text { Pesquisa } \\
\text { de Campo, } \\
\text { Abordagem } \\
\text { Qualitativa }\end{array}$ & $\begin{array}{l}\text { Revista Escola de } \\
\text { Enfermagem USP }\end{array}$ \\
\hline $\begin{array}{c}\text { A Relação entre Enfermeiros, } \\
\text { Mães e Recém-Nascido em } \\
\text { Unidades de Tratamento Intensivo } \\
\text { Neonatal }\end{array}$ & $\begin{array}{l}\text { Gorgulho FR, } \\
\text { Rodrigues } \\
\text { BMRD. }\end{array}$ & 2010 & $\begin{array}{l}\text { Pesquisa } \\
\text { de Campo, } \\
\text { Abordagem } \\
\text { Qualitativa }\end{array}$ & $\begin{array}{c}\text { Revista de Enfermagem } \\
\text { UERJ }\end{array}$ \\
\hline $\begin{array}{c}\text { Promoção de Vínculo Afetivo na } \\
\text { Unidade de Terapia Intensiva } \\
\text { Neonatal: um Desafio para as } \\
\text { Enfermeiras }\end{array}$ & $\begin{array}{l}\text { Conz CA, } \\
\text { Merighl MAB, } \\
\text { Jesus MCP. }\end{array}$ & 2009 & $\begin{array}{l}\text { Pesquisa } \\
\text { de Campo, } \\
\text { Abordagem } \\
\text { Qualitativa }\end{array}$ & $\begin{array}{l}\text { Revista Escola de } \\
\text { Enfermagem USP }\end{array}$ \\
\hline
\end{tabular}


Tabela 1 - Distribuição das pesquisas utilizadas na elaboração dos resultados, 2013.

(conclusão)

\begin{tabular}{|c|c|c|c|c|}
\hline Título & AUTOR & $\begin{array}{c}\text { ANO DE } \\
\text { PuBLICAÇÃo }\end{array}$ & TIPO DE PESQUISA & $\begin{array}{c}\text { Local de Publicação/ } \\
\text { REVISTA }\end{array}$ \\
\hline $\begin{array}{c}\text { Tecnologia e Humanização na } \\
\text { Unidade de Terapia Intensiva } \\
\text { Neonatal: Reflexões no Contexto } \\
\text { do Processo Saúde-Doença }\end{array}$ & $\begin{array}{c}\text { Silva LJ, } \\
\text { Silva LR, } \\
\text { Christoffel MM. }\end{array}$ & 2009 & $\begin{array}{l}\text { Estudo de Caso } \\
\text { Descritivo }\end{array}$ & $\begin{array}{l}\text { Revista Escola de } \\
\text { Enfermagem USP }\end{array}$ \\
\hline $\begin{array}{c}\text { A Percepção da Família sobre } \\
\text { sua Presença em uma Unidade } \\
\text { de Terapia Intensiva Pediátrica e } \\
\text { Neonatal }\end{array}$ & $\begin{array}{l}\text { Molina RCM, } \\
\text { Fonseca EL, } \\
\text { Waldman MAP, } \\
\text { Marcon SS. }\end{array}$ & 2009 & $\begin{array}{l}\text { Pesquisa } \\
\text { de Campo, } \\
\text { Abordagem } \\
\text { Qualitativa }\end{array}$ & $\begin{array}{l}\text { Revista Escola de } \\
\text { Enfermagem USP }\end{array}$ \\
\hline $\begin{array}{c}\text { Experiência de Grupo de Pais em } \\
\text { uma Unidade de Terapia Intensiva } \\
\text { Neonatal }\end{array}$ & $\begin{array}{l}\text { Ferreira JCOA, } \\
\text { Sakita NK, } \\
\text { Ceccon MEJR. }\end{array}$ & 2009 & $\begin{array}{l}\text { Pesquisa } \\
\text { de Campo, } \\
\text { Abordagem } \\
\text { Qualitativa }\end{array}$ & Pediatria (São Paulo) \\
\hline $\begin{array}{c}\text { Presença da Família nas Unidades } \\
\text { de Terapia Intensiva Pediátrica } \\
\text { e Neonatal: Visão da Equipe } \\
\text { Multidisciplinar }\end{array}$ & $\begin{array}{l}\text { Molina RCM, } \\
\text { Bercini LO, } \\
\text { Varela PLR, } \\
\text { Marcon SS, } \\
\text { Castilho AS. }\end{array}$ & 2007 & $\begin{array}{l}\text { Pesquisa } \\
\text { de Campo, } \\
\text { Abordagem } \\
\text { Qualitativa }\end{array}$ & $\begin{array}{c}\text { Revista de Enfermagem } \\
\text { Escola Anna Nery }\end{array}$ \\
\hline $\begin{array}{c}\text { As Expectativas de Pais e } \\
\text { Profissionais de Enfermagem } \\
\text { em Relação ao Trabalho da } \\
\text { Enfermeira em UTIN }\end{array}$ & $\begin{array}{l}\text { Kamada I, } \\
\text { Rocha SMM. }\end{array}$ & 2006 & $\begin{array}{l}\text { Pesquisa } \\
\text { de Campo, } \\
\text { Abordagem } \\
\text { Qualitativa }\end{array}$ & $\begin{array}{l}\text { Revista Escola de } \\
\text { Enfermagem USP }\end{array}$ \\
\hline $\begin{array}{c}\text { Atenção e Cuidado à Família } \\
\text { do Recém-Nascido em Unidade } \\
\text { Neonatal: Perspectivas da Equipe } \\
\text { de Saúde }\end{array}$ & $\begin{array}{c}\text { Tavares AS, } \\
\text { Queiroz MVO, } \\
\text { Jorge MSB. }\end{array}$ & 2006 & $\begin{array}{l}\text { Pesquisa } \\
\text { de Campo, } \\
\text { Abordagem } \\
\text { Qualitativa }\end{array}$ & $\begin{array}{l}\text { Ciência, Cuidado e } \\
\text { Saúde }\end{array}$ \\
\hline $\begin{array}{c}\text { Concepções das Mães sobre os } \\
\text { Filhos Prematuros em UTI }\end{array}$ & $\begin{array}{l}\text { Sales CA, } \\
\text { Alves NB, } \\
\text { Vrecchi MR, } \\
\text { Fernandes J. }\end{array}$ & 2006 & $\begin{array}{l}\text { Pesquisa } \\
\text { de Campo, } \\
\text { Abordagem } \\
\text { Qualitativa }\end{array}$ & $\begin{array}{l}\text { Revista Brasileira de } \\
\text { Enfermagem }\end{array}$ \\
\hline $\begin{array}{c}\text { A Participação da Família no } \\
\text { Cuidado ao Prematuro em UTI } \\
\text { Neonatal }\end{array}$ & $\begin{array}{l}\text { Gaíva MAM, } \\
\text { Scochi, CGS. }\end{array}$ & 2005 & $\begin{array}{l}\text { Pesquisa } \\
\text { de Campo, } \\
\text { Abordagem } \\
\text { Qualitativa }\end{array}$ & $\begin{array}{l}\text { Revista Brasileira de } \\
\text { Enfermagem }\end{array}$ \\
\hline $\begin{array}{c}\text { A Experiência Vivida pelas } \\
\text { Famílias de Crianças } \\
\text { Hospitalizadas em uma Unidade } \\
\text { de Terapia Intensiva Neonatal }\end{array}$ & $\begin{array}{c}\text { Centa ML, } \\
\text { Moreira EC, } \\
\text { Pinto MNGHR. }\end{array}$ & 2004 & $\begin{array}{l}\text { Pesquisa } \\
\text { de Campo, } \\
\text { Abordagem } \\
\text { Qualitativa }\end{array}$ & $\begin{array}{l}\text { Texto \& Contexto } \\
\text { Enfermagem }\end{array}$ \\
\hline $\begin{array}{l}\text { A Influência do Método Mãe- } \\
\text {-Canguru na Recuperação do } \\
\text { Recém-Nascido em Unidade de } \\
\text { Terapia Intensiva Neonatal: uma } \\
\text { Revisão de Literatura }\end{array}$ & $\begin{array}{l}\text { Ferreira L, } \\
\text { Viera CS. }\end{array}$ & 2003 & $\begin{array}{l}\text { Revisão } \\
\text { Bibliográfica }\end{array}$ & $\begin{array}{c}\text { Acta Scientiarum. Health } \\
\text { Sciences }\end{array}$ \\
\hline
\end{tabular}

Fonte: Elaborado pelas próprias autoras, 2013. 
Dos artigos científicos (Tabela 1) selecionados pelos critérios de inclusão previamente estabelecidos, onze $(73,33 \%)$ são pesquisas de campo de abordagem qualitativa, três (20\%) são estudos de caso do tipo descritivo e um $(6,67 \%)$ é de revisão bibliográfica.

Mediante análise, verificou-se que os anos de 2006 e 2009 obtiveram maior número de publicações, respectivamente três e quatro. E os demais anos obtiveram apenas uma publicação em cada ano, exceto o ano de 2008 , em que não foram encontrados artigos que se encaixaram com tema proposto.

Do resumo por similaridade de conteúdos, foi possível evidenciar algumas temáticas dos discursos dos autores, tais como: A família vivenciando o processo de internação - $A$ interação entre a equipe de enfermagem e a família - A família inserida no cuidado ao recém-nascido hospitalizado. Estas, por sua vez, serão desmembradas a seguir.

\section{A FAMÍLIA VIVENCIANDO O PROCESSO DE INTERNAÇÃO}

Durante a gestação, a família aguarda ansiosamente a chegada do seu bebê, criando uma grande expectativa, já que esperam um recém-nascido (RN) sadio que possa ser levado para casa e integrado no seio familiar. ${ }^{(14)}$ Entretanto, nos casos em que o RN precise de internação em uma Unidade de Terapia Intensiva Neonatal (UTIN), ocorre um fato inesperado pela maioria das famílias, desconstruindo a ideia do bebê imaginário.(15,16) Lidar com essa nova rotina é um obstáculo para o qual muitas famílias não estão preparadas, surgindo sentimentos indesejáveis e desencantadores. Esses sentimentos são evidenciados a cada dia, com a chegada dos pais ao domicílio, e a impossibilidade de trazer o neonato consigo, aflorando a sensação de angustia e vazio.

O ambiente da UTIN é marcado por um local novo, afrontoso e pouco acolhedor, gerando para a maioria dos pais, uma dificuldade no processo de interação com o bebê. ${ }^{(14,16,17)}$ São unidades fechadas, frequentemente ruidosas, brilhantes e com grande aparato tecnológico, desencadeando uma barreira para esses pais entrarem em contato direto com seus filhos ${ }^{18}$. Em suas primeiras visitas, é comum os pais desenvolverem sentimentos como medo, insegurança, angústia e ansiedade diante da nova rotina que os espera. ${ }^{(14,18)}$ Surge o medo do desconhecido, sendo necessário o acolhimento dessa família no ambiente da UTIN, principalmente pela equipe de enfermagem que irá lidar com o $\mathrm{RN}$ a todo instante.

A família vivencia um momento delicado e frágil, principalmente a mãe do $\mathrm{RN}$, ao saber que o filho necessita de cuidados especiais, gerando a sensação de impotência, e consequentemente, o sentimento de fracasso como mães. ${ }^{(14)}$ Ocorre a separação da família e RN, sendo este um acontecimento brusco para este, necessitando de intervenções externas, a fim de amenizar as sequelas no desenvolvimento da criança e os aspectos emocionais da mãe. ${ }^{(19,20)}$ É um momento muito delicado e frágil para essa família, surgindo o sentimento de insegurança a respeito do quadro clínico do bebê e assim, minimizando as esperanças de levá-lo para casa. Por conseguinte, poderá ocorrer um comprometimento da participação dos pais na internação, gerando dúvidas acerca da sobrevivência do RN. ${ }^{(14,21)}$

O processo de separação acarreta na mãe a sensação de culpa e perda, além da dificuldade em interagir com a equipe, e o estresse ao qual está submetida, subestimando o seu papel materno. $(19,22,23)$ Há situações em que as mães sentem-se sozinhas e desorientadas acerca do diagnóstico do seu filho, da gravidade e possíveis complicações, principalmente quando recebem a notícia na sala de parto ou em procedimentos pós-parto. ${ }^{(24)}$

A equipe de enfermagem é o elo de aproximação da família com o RN, e o que acontece muitas vezes é a insegurança apresentada pelos pais, tornando-os receosos na participação do cuidado. Cabe ao enfermeiro estimular sua participação, a fim de amenizar os seus sentimentos de impotência e incapacidade em colaborar com a assistência. 


\section{A INTERAÇÃO ENTRE A EQUIPE DE ENFERMAGEM E A FAMÍLIA}

Através da interação com os membros da equipe de saúde e do cuidado prestado ao filho, os pais passam a se ver dentro do processo de hospitalização do mesmo, valorizando o cuidado e dedicação dos profissionais, e assim, construindo uma relação de parceria ${ }^{18}$. A equipe de enfermagem funciona como o principal meio de ligação da família e sua inserção na participação do cuidado ao seu RN na UTIN. (25) Por se tratar de uma unidade fechada de cuidados intensivos, a equipe de enfermagem permanece ao lado do enfermo e a maior parte do tempo com a família, estreitando o vínculo entre os mesmos.

Uma boa recepção da equipe, um tratamento cortês, atenção e preocupação tanto com o RN quanto com a família, são aspectos positivos no relacionamento, do ponto de vista da família. ${ }^{(20)} \mathrm{A}$ família também enxerga o cuidado pelo modo como a equipe de enfermagem se relaciona com o bebê, sendo este considerado o maior fator de relevância para a mesma. Além disso, é observada a confiabilidade dos pais em relação à capacidade da equipe em cuidar do bebê e de manusear os equipamentos ali presentes. ${ }^{(22)}$ Este é o momento em que a equipe de enfermagem, em destaque o enfermeiro, necessita envolver a família, passar confiança e atitude em suas ações, procurando introduzi-la nesse novo ambiente.

Em contrapartida, ficou evidenciado que os familiares percebem determinados pontos dificultadores no processo dessa relação, sendo eles: a falta de identificação dos profissionais da equipe de enfermagem; o foco somente no RN; o distanciamento do enfermeiro com o familiar, e a cobrança da execução dos cuidados pela equipe de forma técnica, ao invés de colaboradora. Muitos familiares não identificam a equipe de enfermagem da unidade por falta de comunicação e muitas vezes, pela falta de identificação, não colaborando para uma boa comunicação. Expressam também o afastamento do enfermeiro diante da situação delicada que a família está vivenciando, enfatizando o não envolvimento destes profissionais. O RN é visto, por algumas equipes, como o alvo da assistência, esquecendo que a família também faz parte desse cuidado. ${ }^{(15,20,22,26)}$

Lidar com cuidados intensivos neonatais é uma prática que exige muita competência e responsabilidade por parte da enfermagem. Quando existe o despreparo da equipe de enfermagem, esta fica insegura para realização da assistência, podendo se tornar um obstáculo nesse relacionamento. ${ }^{(17,22)}$

A comunicação entre os profissionais de saúde e a família é um elemento fundamental no processo de hospitalização de um ente querido, no que se refere à UTIN é ainda mais delicada, por se tratar de um indivíduo tão esperado durante meses. O enfermeiro transfere a transmissão das notícias para médicos, por não querer envolvimento, mesmo tendo conhecimento da situação. ${ }^{(15)}$ A família aguarda ansiosamente por alguma notícia do quadro da criança, por um possível procedimento que irá ser realizado, ou até mesmo por uma simples informação, e muitas vezes o enfermeiro que está responsável pelo $\mathrm{RN}$ não está presente, ou se distancia no momento da visita dos familiares, o que prejudica o meio de comunicação entre eles. $\mathrm{Na}$ troca de informações com esse familiar, o enfermeiro deve adotar uma linguagem clara e acessível para permitir e assegurar uma comunicação efetiva, preservando a singularidade de cada criança e família. ${ }^{(15)}$

Levando-se em conta a importância de tornar o ambiente acolhedor para mãe e filho, o profissional enfermeiro adquire o papel de criar e fortalecer laços afetivos, com o intuito de aproximar a família e minimizar os efeitos negativos referentes ao internamento. ${ }^{(17)}$

\section{A FAMÍLIA INSERIDA NO CUIDADO AO RECÉM-NASCIDO HOSPITALIZADO}

$O$ acolhimento surge como um dos principais métodos para iniciar um processo de assistência humanizada ao RN hospitalizado. A fim de facilitar a inserção da família no ambiente da UTIN, o 
acolhimento tem como proposta receber e atender essas famílias de forma individualizada, proporcionando uma melhor aceitação dos pais para prováveis conflitos emocionais durante o processo de internação, e assim minimizando o seu sofrimento. ${ }^{(25,26)} \mathrm{O}$ enfermeiro tem uma grande responsabilidade ao receber esses familiares, o primeiro contato com o neonato é um momento único que necessita de um profissional disposto a identificar suas necessidades e atender suas dúvidas e anseios diante da situação estabelecida.

O cuidado humanizado envolve a família e a assistência dada pela equipe multiprofissional. Os pais vêem o cuidado humanizado a partir do tratamento fornecido pela equipe, caracterizando-o como educado e respeitoso, ou seja, seu olhar é baseado na atenção e comportamento apresentados pelos profissionais de saúde. ${ }^{(20)}$ Por ser a equipe responsável pelo cuidado e pela maioria dos procedimentos ao bebê, a enfermagem está mais próxima do cotidiano dos recém-nascidos, e assim, necessita compreender a família com integralidade, levando em consideração os aspectos sociais, culturais, psicológicos e econômicos.

É percebido que o avanço da tecnologia causa o distanciamento do familiar ao RN. ${ }^{(22)} \mathrm{O}$ excesso de trabalho que a tecnologia demanda favorece $O$ distanciamento da equipe no cuidado humanizado com a família. ${ }^{(27)}$

A participação da família no cuidado ao RN contribui para um melhor estabelecimento do vínculo afetivo entre os mesmos, facilita a adaptação da criança ao ambiente hospitalar, desenvolve uma relação de confiança entre equipe e família, e minimiza as consequências relacionadas à separação. $(18,26,28) \mathrm{Na}$ percepção dos pais, essa aproximação proporciona uma maior segurança nos procedimentos realizados no filho, e permite-os acompanhar e participar do cuidado, reduzindo seu distanciamento. ${ }^{(15,18,21)}$ Sendo assim, a correta instrução $z \backslash$ dos cuidados e a atenção dispensada pela equipe de enfermagem são fundamentais para estimular a inserção dos pais no cuidado prestado.
À medida que os pais se inserem no cuidado e na recuperação do bebê, despertam o sentimento de ter seu filho de volta, ${ }^{(23)}$ propiciando um ambiente mais acolhedor e prazeroso para esses pais. Sua participação deve ser feita de forma gradual, a partir da ajuda e análise dos profissionais de enfermagem, levando-se em consideração o tempo e a criticidade de cada criança.

Em muitos casos, a presença da família é vista como prejudicial para o trabalho dos profissionais de saúde no que diz respeito a interferências e interrogatórios feitos pelos acompanhantes, dificultando o desenvolvimento das atividades rotineiras. ${ }^{(26,28)}$ Isso ocorre em decorrência de fatores como: pouca sensibilização por partes dos profissionais quanto à importância da presença da família no processo de hospitalização do RN, a falta de capacitação profissional e a estrutura do ambiente inadequada, que muitas vezes dificulta a presença contínua da família. ${ }^{(21,28)}$

Para facilitar o processo de aproximação entre mãe e RN e melhor recuperação do mesmo, foi criado o Método Canguru com o propósito de humanização, independente da tecnologia presente no ambiente da UTIN e de reduzir a taxa de mortalidade neonatal, que se fundamenta em dois objetivos principais: suprir a insuficiência de recursos maternais e evitar a separação prolongada da mãe ao seu RN. ${ }^{(19)}$

A fim de estabelecer uma interação entre os pais e o RN, é necessário que a equipe de enfermagem promova ações que estimulem o cuidado humanizado, levando-se em consideração a singularidade de cada um e o comportamento da família perante a situação. Logo, para que ocorra essa interação, é fundamental implantar ações como: o contato pele a pele, o incentivo ao aleitamento materno, reposicionamento no leito e o estímulo ao dar o banho e a troca da fralda. ${ }^{(18,19,21)}$ Nesse sentido, é importante a orientação e o encorajamento por parte da equipe, possibilitando à família uma maior segurança no cuidado, facilitando a adaptação da criança no ambiente da UTIN. ${ }^{(21,28)}$ 
Muitas famílias enxergam o momento da alta como um desafio, podendo ser tão angustiante quanto o momento do parto. ${ }^{(6)}$ Desse modo, uma família bem orientada e inserida nos cuidados da criança, diminuirá o impacto causado pela alta hospitalar.

\section{CONSIDERAÇÕES FINAIS}

A partir do estudo realizado, concluímos que o estresse provocado pelo processo de internamento proporciona uma série de sentimentos aos familiares de crianças hospitalizadas, uma vez que a separação entre o RN e a família é um momento muito delicado e frágil, gerando nesta sentimentos inesperados e indesejáveis. Deste modo, a equipe de enfermagem é responsável em promover a ligação entre o neonato e a família.

O processo de acolhimento é o ponto inicial para a inserção da família, fazendo-se necessária uma equipe qualificada não só na assistência ao RN, mas também receptiva e gentil para uma boa dinâmica no processo de relacionamento entre a equipe e a família. O cuidado humanizado surge como um aliado no processo de acolhimento; é preciso que a equipe de enfermagem tenha esta visão para uma melhor assistência, pois deve-se pensar no cuidado centrado na família e RN. Foi possível destacar a importância do método mãe-canguru, sendo este imprescindível na humanização da assistência no ambiente da UTIN, surgindo como uma forma de interação dos pais com a criança e a equipe, estreitando os laços afetivos e colaborando na participação do cuidado. Compete ao enfermeiro minimizar o distanciamento entre familiar e neonato, que muitas vezes a tecnologia causa na assistência e promover a aproximação dos mesmos através de uma comunicação clara e efetiva, de acordo com as necessidades de cada família.

O cuidado ao bebê enfatizado pelos familiares traduz uma boa relação, mas é indispensável a identificação da equipe de enfermagem para, assim, estabelecer uma comunicação bem sucedida. No que diz respeito ao nível de conhecimento dos enfermeiros no local de trabalho, viu-se a necessidade de investir no aprimoramento e especialização em cuidados intensivos neonatais, a fim de formar profissionais capacitados para a realização de uma assistência qualificada.

Contudo, a participação da família no cuidado humanizado ao recém-nascido é ainda um tema que precisa receber uma atenção maior. $A$ equipe de enfermagem não só deve incluir a família na sua assistência, como também se sensibilizar e enfrentar as dificuldades em inseri-la no cuidado ao RN, sempre em busca de conhecimentos teóricos que auxiliem nas mudanças necessárias.

\section{REFERÊNCIAS}

1. Lima HF, Rocha SL, Lima de MI. Experiência de pais no cuidar de RN na UTI-N: passando o meu amor, a minha força e minha energia, ele se recupera mais rápido [Monografia]. Goiânia: Universidade Católica de Goiás; 2004.

2. Schmidt KT, Sassá AH, Veronez M, Higarashi IH, Marcon SS. A primeira visita ao filho internado na unidade de terapia intensiva neonatal: percepção dos pais. Rev. Enferm. Esc. Anna Nery. 2012;16(1):73-81.

3. Costa R, Padilha MI. Percepção da equipe de saúde sobre a família na UTI neonatal: resistência aos novos saberes. Rev. Enferm. UERJ 2011;19(2):231-235.

4. BRASIL. Ministério da Saúde. Estatuto da Criança e do Adolescente. Brasília, DF, 2006.

5. Costa da MCG, Arantes MQ, Brito MDC. A UTI Neonatal sob a ótica das mães. Rev. Eletron. Enf. 2010;12(4):698-704.

6. Segre CAM. Perinatologia fundamentos e prática. $1^{a}$ ed. São Paulo: Sarvier; 2002.

7. BRASIL. Ministério da Saúde. Secretaria de Atenção à Saúde. Departamento de Ações Programáticas Estratégicas. Atenção humanizada ao recém-nascido de baixo peso: Método Canguru. Brasília, DF, 2011.

8. Wong DL, Hockenberry MJ, Wilson D, Winkelstein ML. Fundamentos de enfermagem 
pediátrica. $7^{\mathrm{a}}$ ed. Rio de Janeiro: Elsevier; 2006.

9. Pedroso GER, Bousso RS. O significado de cuidar da família na UTI Neonatal: crenças da equipe de enfermagem. Rev. Ciência, Cuidado e Saúde 2003;2(2):123-129.

10. BRASIL. Ministério da Saúde. Secretaria de Atenção à Saúde. Departamento de Ações Programáticas e Estratégicas. Manual AIDPI neonatal. Brasília, DF, $2 \mathrm{Ol2}$.

11. Marconi de MA, Lakatos EM. Metodologia do trabalho cientifico: procedimentos básicos, pesquisa bibliográfica, projeto e relatório, publicações e trabalhos científicos. $7^{a}$ ed. São Paulo: Atlas; 2010.

12. Gil, AC. Como elaborar projetos de pesquisa. $5^{a}$ ed. São Paulo: Atlas; 2010

13. Mendes KDS, Silveira RCCP, Galvão CM. Revisão integrativa: método de pesquisa para incorporação de evidências na saúde e na enfermagem. Tex. Cont. Enferm. 2008; 17(4):758-764.

14. Oliveira K, Veronez M, Higarashi IH, Correa DAM. Vivências de familiares no processo de nascimento e internação se seus filhos em UTI neonatal. Rev. Enferm. Esc. Anna Nery 2013;17(1):46-53.

15. Centa ML, Moreira EC, Pinto MNGHR. A experiência vivida pelas famílias de crianças hospitalizadas em uma unidade de terapia intensiva neonatal. Tex. Cont. Enferm.2004;13(3):444-451.

16. Silva LJ da, Silva LR, Christoffel MM. Tecnologia e humanização na Unidade de Terapia Intensiva Neonatal: reflexões no contexto do processo saúde-doença. Rev. Esc. Enferm. USP 2009;43(3):684-689.

17. Gorgulho FR, Rodrigues BMRD. A relação entre enfermeiros, mães e recém-nascidos em Unidades de Tratamento Intensivo Neonatal. Rev. Enferm. UERJ 2O1O; 18(4):541-546.

18. Molina RCM, Fonseca EL, Waldman MAP, Marcon SS. A percepção da família sobre sua presença em uma Unidade de Terapia Intensiva Pediátrica e Neonatal. Rev. Esc. Enferm. USP 2009;43(3):630-638.
19. Ferreira L, Viera CS. A influência do método mãe-canguru na recuperação do recém-nascido em Unidade de Terapia Intensiva Neonatal: uma revisão de literatura. Acta Scien. Health Scien. 2003;25(1):41-50.

2O. Spir EG, Soares AVN, Wei CY, Aragaki IMM, Kurcgant P. A percepção do acompanhante sobre a humanização da assistência em uma unidade neonatal. Rev. Esc. Enferm. USP 2011;45(5):1048-54

21. Tavares AS, Queiroz MVO, Jorge MSB. Atenção e cuidado à família do recém-nascido em unidade neonatal: perspectiva da equipe de saúde. Rev. Ciência, Cuidado e Saúde 2006;5(2):193-203.

22. Kamada I, Rocha SMM. As expectativas de pais e profissionais de enfermagem em relação ao trabalho da enfermeira em UTIN. Rev. Esc. Enferm. USP 2006;4O(3):404-411.

23. Sales CA, Alves NB, Vrecchi MR, Fernandes J. Concepções das mães sobre os filhos prematuros em UTI. Rev. Bras. Enferm. 2006;59(1):20-24.

24. Ferreira JCOA, Sakita NK, Ceccon MEJR. Experiência de grupo de pais em uma Unidade de Terapia Intensiva Neonatal. Ped. SP 2009;31(1):2O-25.

25. Costa R, Klock P, Locks MOH. Acolhimento na unidade neonatal: percepção da equipe de enfermagem. Rev. Enferm. UERJ 2O12;2O(3):349-353.

26. Gaiva MAM, Scochi CGS. A participação da família no cuidado ao prematuro em UTI Neonatal. Rev. Bras. Enferm. 2005;58(4):444448.

27. Conz CA, Merighi MAB, Jesus MCP de. Promoção de vínculo afetivo na Unidade de Terapia Intensiva Neonatal: um desafio para as enfermeiras. Rev. Esc. Enferm. USP 2009;43(4):849-855.

28. Molina RCM, Varela PLR, Castilho AS, Bercini LO, Marcon SS. Presença da família nas unidades de terapia intensiva pediátrica e neonatal: visão da equipe multidisciplinar. Rev. Enferm. Esc. Anna Nery 2007;11(3):437-444. 